\title{
Pokazać światu polskich Bernardynów, Bossuetów, Wesleyów, Newmanów
}

\author{
ks. Kazimierz Panuśs \\ Uniwersytet Papieski Jana Pawła II w Krakowie \\ kazimierz.panus@upjp2.edu.pl (D) https://orcid.org/0000-0002-9604-2920
}

Kaznodziejstwo w Kościele pełni ważną rolę, głoszenie słowa Bożego jest bowiem obok sprawowania sakramentów jedną z dwóch fundamentalnych funkcji w prowadzonym przez Kościół dziele zbawienia człowieka ${ }^{1}$. Przepowiadanie słowa Bożego ma jednak nie tylko znaczenie teologiczne.

\section{Rola kaznodziejstwa w dziejach kultury polskiej}

W polskiej kulturze kaznodziejstwo odgrywało zawsze wyjątkową rolę. To dzięki niemu w początkach chrystianizacji Polski pierwsi „słudzy Słowa” - jak nazywa św. Łukasz głosicieli Ewangelii (por. Łk 1,2) - w ubogim i surowym języku Słowian wykuwali pojęcia, przy pomocy których przekazywali w sposób zrozumiały dla szerokiego ogółu skomplikowane treści religii chrześcijańskiej. Łaciński i ponadnarodowy Kościół stawał się propagatorem polskości. Dzięki niemu dokonywała się promocja języka polskiego - z kultury przedpiśmiennej do prostego początkowo języka literackiego. Wyjątkową rolę ambony w kulturze polskiej dobrze oddaje fakt, że najstarszym zabytkiem artystycznej prozy polskiej pozostają wciąż Kazania świętokrzyskie. Pochodzą z początku XIV stulecia i są niewątpliwie kopią wcześniejszego trzynastowiecznego rękopisu. Z zachowanych pasków udało się odtworzyć całe kazanie o świętej Katarzynie oraz różnej wielkości fragmenty pięciu innych kazań: Na dzień św. Michała, Na dzień św. Mikołaja, Na Narodzenie Pańskie, Na Objawienie Pańskie, Na Oczyszczenie Najświętszej Marii Panny².

1 A. Lewek, Współczesna odnowa kaznodziejstwa, z. 2, Warszawa 1980, s. 23-24.

2 Zob. m.in. W. Wydra, Wokót fenomenu „Kazań świętokrzyskich”, [w:] Kazania świętokrzyskie. Nowa edycja. Nowe propozycje badawcze, red. P. Stępień, Warszawa 2009, s. 41-58; T. Mika, „Kazania świętokrzyskie”. Od rękopisu do zrozumienia tekstu, Poznań 2012. 
Wysoka ranga kaznodziejstwa utrzymywała się w kolejnych wiekach. Swym oddziaływaniem ogarniało ono wszystkie stany społeczne. Krąg odbiorców kazań wyznaczany stałym rytmem świąt kościelnych i nabożeństw był nieporównywalnie większy niż słowa pisanego, które docierało do stosunkowo nielicznych czytelników. „Wpływ kaznodziejstwa na religijność polską i kulturę narodową - stwierdza Janusz Stanisław Pasierb - był w przeszłości większy niż oddziaływanie książek. Książkę mógł czytać tylko uczony i ten, kogo stać było na kupno książki [...]. Kazań natomiast słuchał nie tylko uczony, ale i prostak, nie tylko bogaty pan czy mieszczanin, ale i chłop pańszczyźniany, nawet żebrak. [...] Kazanie było przez wieki jedynym dla ogromnej większości Polaków źródłem wiary i inspiracji chrześcijańskiej”3. Dzięki kaznodziejstwu dokonywała się katechizacja i formacja religijna wiernych, a przez to zmieniało się oblicze polskiej ziemi. To w nim niczym w zwierciadle odbija się życie religijne i narodowe. Trwałym dziedzictwem tego kaznodziejstwa jest też uczuciowość, działanie na wyobraźnię i wiele ludzkiego ciepła związanego z kultem Jezusa Chrystusa, jego Matki i świętych. Te cechy nadal są obecne w religijności polskiej i wciąż ją kształtująa ${ }^{4}$.

Szczególną rolę pełniła ambona polska w czasie zaborów. To z niej płynęła i docierała do Polaków nie tylko prawda o Bogu, ale i o Ojczyźnie, o jej chlubnej przeszłości i tradycjach narodowych, o potrzebie wolności wewnętrznej i zewnętrznej. Kazania były istotnym czynnikiem sprzyjającym zachowaniu polskości; utrwalały patriotyzm i dążenia niepodległościowe. Kaznodziejstwo brało żywy udział w tym procesie nie tylko jako nośnik treści, medium, lecz także jako katalizator nastrojów i polemik oraz budowniczy, promotor i wychowawca takich postaw ${ }^{5}$.

Także w historii najnowszej w latach powojennych kaznodziejstwo polskie odegrało znaczącą rolę. „Ambona polska stała się szkolną katedrą, surogatem prasy, radia i filmu katolickiego, musiała zastępować pracę w organizacjach i bardzo często - wobec niedokształcenia religijnego - katechizację" ${ }^{\text {. W latach }}$ zniewolenia komunistycznego kaznodziejstwo było „enklawą myśli

3 J. S. Pasierb, Pionowy wymiar kultury, Kraków 1983, s. 91-92.

4 K. Panuś, „Oni torowali pierwsze drogi”. Wkład kaznodziejstwa w podwaliny kultury polskiej, „Ruch Biblijny i Liturgiczny” 69 (2016) nr 4, s. 328, https://doi.org/10.21906/rbl.232.

5 Por. tenże, Pedagogiczny wymiar kaznodziejstwa patriotycznego, [w:] Wychowanie do patriotyzmu, red. W. Janiga, Przemyśl-Rzeszów 2006, s. 529-576.

6 J. S. Pasierb, Od kaznodziejstwa do homilii, Pelplin 1983, s. 15. 
nieocenzurowanej, choć często skazanej na niełatwą sztukę aluzji”" . Dlatego wokół Kościoła skupili się w stanie wojennym prawie wszyscy niezależni twórcy kultury polskiej.

O sile gatunkowej kazania czy homilii może też świadczyć fakt, że współcześni pisarze sięgają po tę formę, niekoniecznie wypowiadając się na tematy teologiczne. Tak czyni choćby Ryszard Przybylski, proponując wspólną lekturę Pisma Świętego ${ }^{8}$.

Już w tym świetle widać, iż kaznodziejstwo polskie jest niezwykle cennym źródłem do poznania kultury religijnej, duchowości i obyczajów, dziejów języka, literatury i sztuki. Jednocześnie ten ogromny obszar jest najbardziej zaniedbanym badawczo działem naszego piśmiennictwa. Ciągle niezadowalający jest też stan prac edytorskich nad tego rodzaju źródłami.

\section{Projekty Kazania w kulturze polskiej. Edycje kolekcji tematycznych}

Zaradzić temu starają się dwa projekty pt. Kazania w kulturze polskiej. Edycje kolekcji tematycznych finansowane w latach 2012-2019 z Narodowego Programu Rozwoju Humanistyki. Kierownikiem pierwszego projektu, którego celem była naukowa edycja kazań maryjnych, pasyjnych i funeralnych, był ks. Kazimierz Panuś z Uniwersytetu Papieskiego Jana Pawła II w Krakowie, badacz kaznodziejstwa dwóch ostatnich stuleci, a wykonawcami wybitni znawcy piśmiennictwa epok dawnych i mistrzowie edytorstwa naukowego: Roman Mazurkiewicz z Uniwersytetu Pedagogicznego im. Komisji Edukacji Narodowej w Krakowie, autor odkrywczych monografii, m.in. Deesis. Idea wstawiennictwa Bogarodzicy i św. Jana Chrzciciela w kulturze średniowiecznej (wyd. 3, Kraków 2012); Marek Skwara z Uniwersytetu Szczecińskiego, bibliograf i edytor funeraliów staropolskich oraz Janusz S. Gruchała, kierownik Katedry Edytorstwa na Uniwersytecie Jagiellońskim i wydawca kazań Piotra Skargi ${ }^{9}$.

Kontynuację tych studiów źródłowych, edytorskich i interpretacyjnych nad kaznodziejstwem polskim stanowił drugi projekt, którego tematem stały się kazania adwentowe opracowane przez ks. Witolda Ostafińskiego,

7 J. Miodek, Współczesne kaznodziejstwo polskie, [w:] Tysiąc lat polskiego słownictwa religijnego, red. B. Kreja, Gdańsk 1999, s. 265.

8 Zob. R. Przybylski, Homilie na Ewangelię Dzieciństwa, Paryż 1990, Warszawa 2007.

9 A. Nowicka-Jeżowa, Polska ars praedicandi. Od Peregryna z Opola do Karola Wojtyły, „Barok. Historia-Literatura-Sztuka” 2016 nr 45/46, s. 247. 
wielkanocne - przez Janusza S. Gruchałę, patriotyczne - przez Marka Skwarę i bożonarodzeniowe - przez Annę Jungiewicz z Uniwersytetu Jagiellońskiego. Projektem kierował ks. Kazimierz Panuś, opracował też najbardziej reprezentatywne kazania XIX, XX i XXI wieku.

\section{Seria Kazania w Kulturze Polskiej. Edycje Kolekcji Tematycznych}

W siedmiu edycjach naukowych kazań zawierających publikację wyników ${ }^{10}$ dwóch projektów pt. Kazania w kulturze polskiej. Edycje kolekcji tematycznych zamieszczone zostały teksty zarówno znanych i docenianych kaznodziejów, jak i mówców minorum gentium. Na ponad czterech tysiącach stron zaprezentowano szeroką panoramę historyczną kaznodziejstwa polskiego od średniowiecza do współczesności ${ }^{11}$.

W każdym z 7 tomów serii utrzymany został jednakowy schemat. Na początku każdego z nich zamieszczono słowo redaktora i wprowadzenie, wykaz skrótów, a następnie edycje kazań zawierające polski tekst kazania (w wersji oryginalnej lub tłumaczonej), podstawę wydania, notę biograficzną, wybraną bibliografię oraz objaśnienia. Każdy tom zamyka obszerny indeks osób, a tomy 4-7 - również tłumaczenie wprowadzenia na język angielski.

Poczet kaznodziejów staropolskich otwierają dwaj średniowieczni dominikanie o europejskiej sławie i autorytecie osobistym, który zapewnił im wysokie urzędy w Kościele: Marcin Polak z Opawy (zm. 1279) i Peregryn z Opola (zm. po 1333). Pierwszy był arcybiskupem nominatem gnieźnieńskim, drugi prowincjałem Zakonu Kaznodziejskiego. W antologiach zamieszczone są dwa

10 Kazania maryjne, wyd. i oprac. R. Mazurkiewicz, K. Panuś, Kraków 2014, https://doi.org/10.21906/ 9788376431468; Kazania funeralne, wyd. i oprac. K. Panuś, M. Skwara, Kraków 2014, https://doi. org/10.21906/9788376431475; Kazania pasyjne, wyd. i oprac. J. S. Gruchała, K. Panuś, Kraków 2014, https://doi.org/10.21906/9788376431482; Kazania wielkanocne, wyd. i oprac. J. S. Gruchała i K. Panuś, Kraków 2019, https://doi.org/10.21906/9788376431833; Kazania adwentowe, wyd. i oprac. W. Ostafiński i K. Panuś, Kraków 2019, https://doi.org/10.21906/9788376431697; Kazania bożonarodzeniowe, wyd. i oprac. A. Jungiewicz i K. Panuś, Kraków 2019, https://doi.org/10.21906/ 9788376431796; Kazania patriotyczne, wyd. i oprac. K. Panuś i M. Skwara, Kraków 2019, https:// doi.org/10.21906/9788376431819.

11 Por. A. Nowicka-Jeżowa, Polska ars praedicandi. Od Peregryna z Opola do Karola Wojtyly, dz. cyt.; K. Bracha, Is It Worth Publishing Anthologies of Sermons? On the Margins Kazania $w$ kulturze polskiej. Edycje Kolekcji Tematycznych [Sermons in Polish Culture. Editions of Thematic Collections], ed. Kazimierz Panuś, vols. 1-3, Wydawnictwo UNUM, Kraków 2014, pp. 1849, „Res Historica” 2019 nr 47, s. 333-348, https://doi.org/10.17951/rh.2019.47.333-348. 
kazania Marcina (Na III Niedzielę Adwentu, Kazanie na Narodzenie Pańskie) i trzy Peregryna (Na święto Narodzenia Najświętszej Maryi Panny, Na Święto Obrzezania Pana, Na Zmartwychwstanie Pańskie).

Po nich następują predykanci końca XIV i pierwszych dekad wieku XV, którzy reprezentują wysoką kulturę teologiczną, erudycję biblijną i patrystyczną, głęboką pobożność, zaangażowanie w pracy duszpasterskiej i reformatorskiej. W antologiach reprezentuje ich scholastyk europejskiej sławy Mateusz z Krakowa (Kazanie na Wniebowzięcie błogosławionej Maryi, Kazanie o Niewiniątkach), anonimowy autor polskiego już Kazania drugiego na dzień Bożego Narodzenia zapisanego w zbiorze Kazań Gnieźnieńskich oraz autor znanego w Europie dzieła o sakramentach, słynny kaznodzieja mariacki Mikołaj z Błonia zwany Pszczółką. Należy podkreślić, że jego trzy kazania: O zwiastowaniu Maryi, Niedziela w Oktawie Narodzenia Pańskiego. Kazanie XIII oraz Na święty dzień Zmartwychwstania zostały po raz pierwszy przełożone z łaciny, podobnie jak wspomniane kazania Mateusza z Krakowa. Ważny głos zabierają pierwsi rektorzy odnowionej Akademii Krakowskiej: Stanisław ze Skarbimierza (zm. 1431) i Franciszek z Brzegu (zm. 1432), sławiąc w swych kazaniach królową Jadwigę i jej wkład w to wiekopomne dzieło.

Wydobycie tych tekstów spoczywających in oblivione et pulvere w bibliotekach i archiwach jest niewątpliwie dużym osiągnięciem zespołów badawczych realizujących oba projekty. Szacuje się bowiem, że kolekcje kazań stanowią aż 40 procent z około 8 tysięcy średniowiecznych manuskryptów zachowanych w Polsce. Także większość starodruków to zbiory kazań ${ }^{12}$. Nadal wiele z nich jest wciąż nieznanych polskiej kulturze, bądź ulega degradacji na skutek upływu czasu. Tak jest na przykład z kazaniem Łukasza z Wielkiego Koźmina De sancto Briccio et rege in missa Universitatis (rkps BJ 2215, k. 162v-168) wygłoszonym 13 listopada 1410 roku i zawierającym pochwałę króla Władysława Jagiełły i jego obronę przed zarzutami wysuwanymi przez propagandę krzyżacką. Pierwotnie zamierzano zamieścić go w tomie kazań patriotycznych. Wystąpiły jednak problemy natury paleograficznej. Tekst ten jest w wielu miejscach wyblakły i nieczytelny. Dlatego też ważną grupę kazań poświęconych wiktorii grunwaldzkiej ${ }^{13}$ i jej zwycięskiemu królowi reprezentują dwa teksty po raz pierwszy przełożone z łaciny na język polski i opublikowane

12 Por. K. Bracha, Is it worth publishing anthologies of sermons?..., dz. cyt., s. 336.

13 Zob. tenże, Święto wiktorii grunwaldzkiej w kaznodziejstwie polskim późnego średniowiecza, [w:] Conflictus magnus apud Grunwald 1410. Między historią a tradycją, red. K. Ożóg, J. Trupinda, Malbork 2013, s. 231-247. 
w całości. Są to Jana z Kluczborka (ok. 1370-1436) Kazanie o godności królewskiej na cześć króla Władysława Jagiełty, królowej Anny Cylejskiej i wielkiego księcia litewskiego Witolda powstałe ok. 1410-1411 oraz Sermo de divisione apostolorum o incipicie Convocavit Ihesus XII discipulis nieznanego autora odczytane z rękopisu kodeksu znajdującego się w Bibliotece Klasztoru Paulinów na Skałce w Krakowie (rękopis B 23).

Wiek szesnasty otwiera zamieszczone w tomie 1 kazanie $O$ poczęciu Maryjej Panny czystej przypisywane bernardynowi Janowi z Szamotuł zwanemu Paterkiem (zm. 1519). Złoty wiek, a szczególnie ostatnie jego trzydziestolecie, to okres rozwoju kaznodziejstwa katolickiego, odnowionego w duchu trydenckim, wzmocnionego do walki z reformacją orężem humanae litterae i tradycji patrystycznej. Na tej fali powstały kazania jezuitów: Jakuba Wujka (zm. 1597), tłumacza Biblii, i jednego z cenzorów tego przekładu Stanisława Grodzickiego (zm. 1613) zwanego apostołem Litwy. W tym duchu powstają też kazania opata mogilskiego, a następnie biskupa kamienieckiego Marcina Białobrzeskiego (zm. 1586), prymasa Stanisława Karnkowskiego (zm. 1603) oraz kaznodziejów nadwornych króla Stefana Batorego: Stanisława Sokołowskiego (zm. 1593) i Hieronima Powodowskiego (zm. 1613). Ich kazania są obecne w różnych tomach serii.

W panoramie kaznodziejstwa polskiego szczególne miejsce zajmuje Piotr Skarga SJ (zm. 1612), znakomity kaznodzieja króla Zygmunta III, autor staropolskiego bestselleru Żywotów świętych i słynnych Kazań sejmowych.

Kolejne kazania licznie zamieszczone w 7 tomach serii wyszły spod pióra protestantów. W panoramę kaznodziejstwa polskiego wyraźnie wpisali się działacze, polemiści i kaznodzieje kalwińscy. Reprezentują ich organizator szkolnictwa ewangelickiego i tłumacz Biblii Grzegorz Orszak (ok. 1567) oraz jeden z ojców literatury polskiej Mikołaj Rej (zm. 1569). Teologami i kaznodziejami kalwińskimi byli Grzegorz z Żarnowca (zm. 1601), Paweł Gilowski (zm. 1595) i agresywny polemista Krzysztof Kraiński (zm. 1618). Obszerne objaśnienia jego kazań zamieszczonych w 1 i 6 tomie ukazują erudycję mówcy, ale w niemniejszym stopniu demagogię polemiki, demaskują także liczne zapożyczenia ze Złotej legendy, które pozostają w sprzeczności z inwektywami na „zabobon rzymski”. Teksty kaznodziejów protestanckich dokumentują ofensywę reformacyjną, której apogeum przypada na okres panowania Zygmunta Augusta, utrwalają strategie retoryczne protestantów, radykalizację poglądów i kształtujący się w atmosferze walki wyznaniowej model religijności.

Z kaznodziejów luterańskich nie mogło zabraknąć Samuela Dambrowskiego (zm. 1625). Jego Postylla chrześcijańska (Toruń 1620-1621) przeznaczona dla 
prostych odbiorców zdobyła niezwykłą popularność. Pastorem i kaznodzieją luterańskim na Śląsku był również Konrad Negius (zm. 1617), autor postylli dla prostych wiernych $\mathrm{z}$ wiejskich parafii. Zamieszczone w tomie 4 serii Contio na dzień świętej Wielkonocy Anno 1577 pochodzi z kopii autografu wykonanego w okresie międzywojennym dla prof. Henryka Barycza. Również luterańskiej proweniencji jest kazanie Na Poniedzialek Wielkonocny Christiana Langhansena wyjęty z Postylli dla dziatek abo młodzi chrześcijańskiej przełożonej na język polski z niemieckiego przez Krzysztofa Haberkanta w wieku XVIII.

Reprezentantami Rusi są w serii teologowie prawosławni, a następnie unici: hierarcha Melecjusz Smotrycki (Kazanie na Niedzielę po Narodzeniu Pańskim) i pisarz religijny Cyryl Trankwilion Stawrowiecki (Pouczenie na Przesławny Dzień Narodzenia Pana Boga i Zbawiciela Naszego Jezusa Chrystusa). W ten sposób projekt Kazania w kulturze polskiej wydobywa trzeci, wschodni ton homiletyki staropolskiej. Reprezentujący go autorzy dziedziczą tradycje Wschodu, ale także i Zachodu przez wykształcenie w kolegiach jezuickich i przyjęcie unii.

Z bogatych zasobów kaznodziejstwa doby baroku opracowane zostały kazania, które głosili biskupi: Stanisław Szembek (zm. 1721) i Andrzej Chryzostom Załuski (zm. 1711), uczeni kapłani: rektor Akademii Krakowskiej Adam Opatowczyk (zm. 1647), słynny polihistor Szymon Starowolski (zm. 1656) i kanonik krakowski Jakub Ostrowski (zm. 1638), wybitni teologowie: Sebastian Stryjewicz (zm. 1681) z Akademii Krakowskiej, Kazimierz Jan Wojsznarowicz (zm. 1677) związany z Akademią Wileńską i dworem Radziwiłłów oraz Maciej Józef Łubieński (zm. 1770).

W 7 tomach serii niezwykle licznie reprezentowani są mówcy z różnych zakonów. Barokowe kaznodziejstwo dominikańskie dobrze wyraża Fabian Birkowski OP (zm. 1636), następca Skargi na stanowisku kaznodziei królewskiego. Z Zakonu Kaznodziejskiego wywodzą się także Stanisław Abraham Bzowski (zm. 1637), Gabriel Leopolita Zawieszko (zm. 1646), Jacek Marcin Mijakowski (zm. 1647) i Augustyn Rakiewicz (zm. po 1712), dominikanin prowincji litewskiej. Kaznodziejstwo cystersów reprezentuje mariolog i kaznodzieja Andrzej Karp (zm. 1678), augustianów - Jan Chryzostom Gołębiowski (zm. 1700), kanoników regularnych laterańskich - Stanisław Zakrzewski (zm. 1631) i Jacek Liberiusz (zm. 1673), pijarów - Benedykt Zawadzki (zm. 1703), Józef Kazimierz Madejski (zm. 1746), Samuel Wysocki (zm. 1771) i Jan Franciszek Włocki (zm. 1773), a paulinów - Dominik Paprocki (zm. 1729), jeden z kaznodziejów, który w 1717 roku wygłosił na Jasnej Górze kazanie z okazji koronacji cudownego wizerunku NMP koronami papieskimi. 
Franciszkańskie kaznodziejstwo barokowe przybliżają reformaci: Bernard Gutowski (zm. 1696), Antoni Węgrzynowicz (zm. 1721) i Franciszek Rychłowski (zm. 1673), franciszkanie konwentualni: Walerian Gutowski (zm. 1693) i Bazyli Rychlewicz (zm. 1710) oraz bernardyni: Antoni Stefanowicz (zm. 1679) i Adrian Seriewicz (zm. 1748).

Najliczniejszą reprezentację kaznodziejstwa barokowego tworzą jezuici: Jakub Olszewski (zm. 1634), Marcin Hińcza (zm. 1668), Paweł Kaczyński (zm. 1676), Tomasz Młodzianowski (zm. 1686), Jan Ignacy Krosnowski (zm. 1697), Bonawentura Gelarowski (zm. 1711), Jan Wolski (zm. 1729), Franciszek Kowalicki (zm. 1730), Antoni Czerniewski (zm. 1732), Jan Zrzelski (zm. 1746), Andrzej Murczyński (zm. 1748), Wawrzyniec Rydzewski (zm. 1765), Jan Bielski (zm. 1768), Konstanty Awedyk (zm. 1771)i Atanazy Ludwik Kierśnicki (zm. 1733), jeden z najwybitniejszych kaznodziejów pierwszej połowy XVIII wieku.

W drugiej połowie XVIII wieku w epoce stanisławowskiej pojawiają się nowe idee twórcze związane z polskim oświeceniem. Kaznodzieje podejmują program reform mających na celu ratowanie kraju, edukację, walkę z wadami narodowymi i troskę o umiłowanie ojczyzny. W różnych tomach serii tematyka ta przewija się w kazaniach franciszkanów: Kasjana Korczyńskiego (zm. 1784) i Józefa Męcińskiego (1748-1814), karmelity bosego Maksymiliana Karpowicza (zm. 1770), jezuity Andrzeja Filipeckiego (zm. 1792), paulinów: Teodora Grubera (zm. 1808) i Fortunata Opełczyńskiego, dominikanina, a później biskupa pomocniczego żmudzkiego Antonina Malinowskiego (zm. 1816), benedyktyna Nepomucena Adriana Dębskiego (zm. po 1800). W służbę zagrożonej ojczyzny i program reform włączyli się także kaznodzieje wywodzący się z duchowieństwa diecezjalnego, czego dowodzą kazania kanonika płockiego i krakowskiego Augustyna Lipińskiego (zm. 1814), kaznodziei w kolegiacie lubelskiej Benedykta Józefa Czajkowskiego i najbardziej reprezentatywnego mówcy ówczesnej epoki Michała Franciszka Karpowicza (zm. 1803), pierwszego biskupa wigierskiego, nazywanego Chryzostomem polskiej ambony.

W każdym tomie serii wyodrębniona została część druga, w której zamieszczone są kazania z XIX, XX i XXI wieku. Jest to najpierw czas rozbiorów. Głoszone wtedy po polsku kazania były „istotnym czynnikiem sprzyjającym zachowaniu polskości; częstokroć były także rękojmią patriotyzmu i dążeń niepodległościowych”" ${ }^{14}$. Okres ten reprezentują mowy i kazania prymasa

14 B. Śniecikowska, Kazanie [w:] Słownik rodzajów i gatunków literackich, red. G. Gazda i S. TynieckaMakowska, Kraków 2006, s. 345. 
Jana Pawła Woronicza (zm. 1829), uczonego pijara Stefana Przeczytańskiego (zm. 1817) i Józefa Wincentego Łańcuckiego (zm. 1841), któremu dane było żegnać wielkich wodzów: księcia Józefa Poniatowskiego i generała Tadeusza Kościuszkę. W kolejnych latach dobę zaborów w kaznodziejstwie polskim przywołują teksty profesora Uniwersytetu Warszawskiego Feliksa Ustrzyckiego (zm. 1834), abpa Ignacego Hołowińskiego (zm. 1855), prekursora odnowy biblijno-kerygmatycznej w przepowiadaniu, wybitnego misjonarza ludowego i poety Karola Antoniewicza (zm. 1852), kaznodziei warszawskiego kościoła Świętego Krzyża Tomasza Bojanowskiego CM (zm. 1854), proboszcza łęczyckiego oraz wykładowcy Akademii Duchownej Warszawskiej Józefa Kalasantego Mętlewicza (zm. 1858) oraz wybitnego kaznodziei Krakowa i Warszawy, działacza społecznego ks. Zygmunta Goliana (zm. 1885). Przełom XIX i XX wieku naznaczony został wyraźnie przez mowy bpa Józefa Sebastiana Pelczara (zm. 1924), kanonizowanego w 2003 roku, i jego biskupa pomocniczego Karola Józefa Fischera (zm. 1931), powstańca styczniowego, a potem profesora historii Kościoła Uniwersytetu Jagiellońskiego Władysława Chotkowskiego (zm. 1926), profesora teologii pastoralnej i dziekana Wydziału Teologicznego Uniwersytetu Jagiellońskiego Józefa Krukowskiego (zm. 1900), metropolity lwowskiego obrządku ormiańskiego Izaaka Mikołaja Isakowicza (zm. 1901), pijara Tadeusza Chromeckiego (zm. 1901), wybitnego kaznodziei jezuickiego Józefa Stanisława Adamskiego (zm. 1926) oraz świątobliwego i aktywnego w całej Europie redemptorysty Bernarda Łubieńskiego (zm. 1933).

Kaznodziejstwo emigracyjne troszczące się o identyczność kulturową i narodową Polaków reprezentują działający w Paryżu i Rzymie wielcy zmartwychwstańcy: porównywany z Piotrem Skargą Hieronim Kajsiewicz (zm. 1873), filozof i działacz katolicki Piotr Semenenko (zm. 1886) oraz cieszący się opinią dobrego kaznodziei Aleksander Jełowicki (zm. 1877).

W serii zaznaczony jest jeszcze jeden nurt ważny dla kultury polskiejkaznodziejstwo żydowskie. Reprezentują go dwa teksty: Izaaka Cylkowa (zm. 1908) i Ozjasza Thona (zm. 1936). Pierwszy z nich 26 września 1878 roku wygłosił w języku polskim mowę przy otwarciu Nowej Synagogi w Warszawie, łamiąc zakaz głoszenia kazań w języku polskim wydany przez zaborcę po stłumieniu powstania styczniowego. Drugi jako kaznodzieja i rabin synagogi postępowej Tempel w Krakowie wygłosił przemówienie do młodzieży szkolnej 16 czerwca 1898 roku w stulecie urodzin Adama Mickiewicza.

Czasy I wojny światowej i międzywojnia reprezentują kazania działacza niepodległościowego i kaznodziei Legionów Polskich bpa Władysława 
Bandurskiego (zm. 1932), ormiańsko-katolickiego arcybiskupa Lwowa Józefa Teodorowicza (zm. 1938), Konstantego Marii Żukiewicza (zm. 1948) i kaznodziei Warszawy Antoniego Władysława Szlagowskiego (zm. 1956), słynnego proboszcza tyskiego Jana Kapicy oraz bpa Stanisława Okoniewskiego (zm. 1944). Z tych czasów pochodzą jeszcze zamieszczone w antologiach kazania utalentowanego mówcy i redaktora „Przewodnika Katolickiego” Józefa Kłosa (zm. 1938), redaktora „Roczników Katolickich” Nikodema Cieszyńskiego (zm. 1942) oraz działającego na Pomorzu Pawła Kirsteina (zm. 1939).

Dramat II wojny światowej przypominają dwa kazania: bł. Henryka Hlebowicza (zm. 1941) Na Trzeci Maj wygłoszone do młodzieży w Wilnie 3 maja 1941 roku oraz bpa Józefa Gawliny (zm. 1964) Kazanie na uroczystość Wielkanocy wygłoszone w Obozie Uchodźców Polskich w Teheranie w Persji 5 kwietnia 1942 roku.

Swoją znakomitą reprezentację mają kazania i homilie okresu powojennego. Głoszą je tak wybitni przedstawiciele polskiej ambony jak Prymas Tysiąclecia kard. Stefan Wyszyński (zm. 1981) i pierwszy Polak na Stolicy Piotrowej kard. Karol Wojtyła (zm. 2005). Wtórują im Stanisław Gawlik (zm. 1980), bł. Jerzy Popiełuszko (zm. 1984), bp Jan Pietraszko (zm. 1988), Julian Michalec (zm. 1988), Jan Zieja (zm. 1991), Janusz Stanisław Pasierb (zm. 1993), Włodzimierz Sedlak (zm. 1993), Józef Maria Bocheński (zm. 1995), Jerzy Chowańczak (zm. 1995), Stanisław Grzybek (zm. 1998), Józef Tischner (zm. 2000), Jan Twardowski (zm. 2006), abp Kazimierz Majdański (zm. 2007), abp Ignacy Tokarczuk (zm. 2012), bp Jan Bernard Szlaga (zm. 2012), Mieczysław Maliński (zm. 2017), bp Wacław Świerzawski (zm. 2017), Bronisław Mokrzycki (zm. 2017), Piotr Pawlukiewicz (zm. 2020) i ujmujący słuchaczy swoją formą adresatywną „Kochani moi” bp Józef Zawitkowski (zm. 2020).

Kazania tych twórców reprezentują heroiczny udział duchownych w historii Polski pod zaborami, w wolnym dwudziestoleciu i w czasie obu wojen, na koniec w dobie komunistycznego reżimu i walki o suwerenność. Wygłaszane na polach walki Legionów, II wojny światowej, podczas stanu wojennego i zmagań Solidarności nie tylko upamiętniały najważniejsze wydarzenia, ale je współtworzyły, kształtując etos Polaków, kierując błądzące nieraz emocje i porywy na drogę właściwą narodowi chrześcijańskiemu. Rękojmią skutecznej perswazji był nie tylko szlachetny patos (Władysław Bandurski), nie tylko mistrzowska retoryka (Jan Pietraszko) czy oryginalna, atrakcyjna dla ówczesnych odbiorców forma przekazu (Mieczysław Maliński), ale też - i przede wszystkim - świadectwo życia (Paweł Kirstein, Józef M. Bocheński i wielu innych) oraz osobista świętość wielu kaznodziejów - sług Bożych, błogosławionych i świętych. 
W antologiach nie zapomniano o aktualnie działających siewcach słowa Bożego, których kazania przyciągają uwagę szerokiego gremium. Wyrazem tego są homilie Edwarda Stańka, znawcy literatury ojców Kościoła, rekolekcjonisty, wychowawcy kapłanów i kaznodziejów; Mirosława Drzewieckiego, słynnego kaznodziei wrocławskiego, i Michała Hellera, wybitnego filozofa przyrody. Owocami swojej wiary i przemyśleń nad ojczystą kulturą dzielą się pasterze Kościoła w Polsce. W antologiach zamieszczono teksty kard. Stanisława Dziwisza, arcybiskupów: Stanisława Gądeckiego, Marka Jędraszewskiego i Józefa Michalika oraz bpa Gerarda Kusza.

Siedem dotychczas wydanych tomów omawianej serii prezentuje kazania 148 mówców. Teksty niektórych z nich pojawiają się kilkakrotnie. Najwięcej, łącznie 6 kazań zostało zaczerpniętych z dorobku Piotra Skargi i Fabiana Birkowskiego, po 4 ze spuścizny Mikołaja Reja, Jacka Liberiusza, Franciszka Rychłowskiego i Jana Pawła Woronicza. Już samo wyliczenie kaznodziejów ujawnia szeroką panoramę kaznodziejstwa polskiego w całej jego różnorodności środowiskowej (uczeni, hierarchowie, zakonnicy wielu zgromadzeń, duszpasterze, działacze społeczni etc.), a także intelektualnej, konfesyjnej i retorycznej. Antologie śledzą następujące po sobie konwencje: średniowieczną formację scholastyczną, dyskurs wojującej reformacji, poetykę wywodzącą się z humanistycznego renesansu, nasycającą się z czasem elementami barokowego „piękna rozmaitego”, styl wzrastający na gruncie prawosławnego Wschodu, katechezę oświeceniową, tendencje neoscholastyczne, aż po odnowę biblijno-kerygmatyczną w przepowiadaniu XX-wiecznym. Antologie - jak podkreśla Alicja Nowicka-Jeżowa - „wskazują tendencje charakterystyczne dla biblistyki i retoryki kolejnych epok, utrwalają liturgię i obrzędowość świąt Narodzenia, Męki i Zmartwychwstania Chrystusa oraz uroczystości maryjnych; odzwierciedlają wiedzę o świecie, zarówno akademicką, jak ludową, mentalność i cechy pobożności zbiorowej. Nie pomijają też konceptualnych

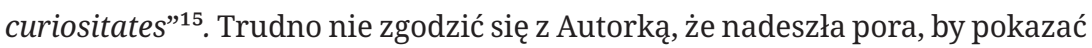
światu polskich Bernardynów, Bossuetów, Wesleyów, Newmanów ${ }^{16}$.

15 A. Nowicka-Jeżowa, Polska ars praedicandi. Od Peregryna z Opola do Karola Wojtyły, dz. cyt., s. 248. kultu Imienia Jezus, przywódca reformy franciszkanów obserwantów, w Polsce zwanych od jego imienia bernardynami, święty Kościoła katolickiego; Jacques Bénigne Bossuet (1627-1704), wybitny kaznodzieja francuski, czołowy przedstawiciel kaznodziejstwa klasycznego, sukcesy na ambonie zjednały mu przydomek „Orzeł z Meaux”; członek Akademii Francuskiej, wychowawca syna następcy tronu Ludwika XIV, biskup Meaux; John Wesley (1703-1791), duchowny Kościoła anglikańskiego, współzałożyciel metodystów, prowadził działalność kaznodziejską w czasie 


\section{Kryteria doboru tekstów i zasady wydania}

Kwalifikując kazania do edycji naukowej, starano się zapewnić reprezentatywność dla poszczególnych epok, uwzględnić kryterium tematyczno-liturgiczne, wyznaniowe (kazania katolickie, prawosławne, protestanckie, żydowskie), wartości teologiczne i literackie oraz język, w którym zostały zapisane (łaciński, polski i cerkiewnosłowiański). Wykonawcy projektu zadbali o to, by zebrany materiał odzwierciedlał w możliwie proporcjonalnym stopniu dorobek kolejnych stuleci i epok z wyraźną jednak preferencją dla kazań dawnych, powstałych przed końcem XVIII stulecia, najmniej znanych, trudno dostępnych, wymagających szczegółowego i zazwyczaj dość specjalistycznego komentarza. Podział ten, który znajduje odzwierciedlenie w dwóch częściach każdego tomu serii, wprowadzono ze względu na odmienność zasad edytorskich obowiązujących przy wydawaniu tekstów staropolskich (do połowy XVIII wieku) oraz tekstów późniejszych. Część pierwsza obejmuje ponadto zabytki powstałe w okresie istnienia I Rzeczypospolitej, uwzględnia więc także kazania powstałe np. na jej wschodnich kresach.

W poszczególnych tomach serii znalazły się kazania wybitnych mówców kościelnych, lecz także twory rzemieślników ambony, teksty klarowne i klasycznie skomponowane, ale też reprezentujące barokową barwność myśli i stylu. Obok tekstów niektórych wybitnych kaznodziejów zamieszczone zostały teksty mniej znane, a warte zainteresowania. Przywraca to zbiorowej pamięci autorów de facto zapomnianych. Teksty kazań oprócz wyjaśnienia dawnych wyrazów i form językowych posiadają polihistoryczne komentarze, jasne i dokładne noty biograficzne, wnikliwe i ciekawe objaśnienia historyczno-kulturowe, a także trafne odnośniki komparatystyczne do piśmiennictwa teologicznego. Ponadto rozpoznanie struktury artystycznej kazań warunkuje prawidłową ich interpretację ${ }^{17}$.

Wykonawcy projektu zakładają, że odbiorcami edycji będą nie tylko badacze dziejów kaznodziejstwa, ale także historycy literatury sensu largo, teologowie, kulturoznawcy. Pozwoliło to ograniczyć komentarze historyczne

rewolucji przemysłowej w Anglii, zwracał się do najuboższych mieszkańców wielkich miast, kazania głosił pod gołym niebem lub w miejscach pracy; John Henry Newman COr (1801-1890), konwertyta z anglikanizmu, jeden z liderów ruchu oksfordzkiego, filozof, teolog, kaznodzieja uniwersytecki, kardynał od 1879, święty Kościoła katolickiego.

17 M. Hanusiewicz-Lavallee, Wspótczesne metody badań nad staropolską literaturą religijną, „Roczniki Humanistyczne" 56 (2008) z. 1, s. 29. 
i merytoryczne do niezbędnego minimum. Komentarz językowy dotyczył przede wszystkim słów i fraz, które wyszły z użycia lub zmieniły znaczenie i utrudniają dziś odbiór tekstu ${ }^{18}$. Ważną sprawą pozostaje także zlokalizowanie cytatów lub kryptocytatów z tekstów przywoływanych przez dawnych autorów ${ }^{19}$. Z kolei objaśnienia merytoryczne odnoszą się do wydarzeń, postaci, miejsc, realiów historycznych i innych kwestii potrzebnych do zrozumienia tekstu. Interteksty uwzględniają Biblię, pisma ojców Kościoła oraz inne dzieła i źródła wskazane przez autorów lub zidentyfikowane przez zespół wykonawców.

Analizowane wyżej antologie kazań wnoszą cenny wkład w studia nad piśmiennictwem religijnym, zmierzając do poznania chrześcijaństwa polskiego, przenikającego tysiącletnią historię i współczesność, formującego kulturę duchową i tożsamość narodową. Warto podążyć drogą wyznaczoną przez autorów serii Kazania w Kulturze Polskiej, bowiem zasoby źródłowe naszej literatury religijnej są ogromne i pozostają wciąż w dużej mierze niewyzyskane badawczo. Równocześnie trzeba też przekazywać gromadzoną wiedzę nieznającemu jej zarówno naszemu społeczeństwu, jak i nauce zagranicznej, gdyż ambona polska posiada wielkich bohaterów zdolnych nosić miano polskich Bernardynów, Bossuetów, Wesleyów czy Newmanów.

\section{Abstrakt}

\section{Pokazać światu polskich Bernardynów, Bossuetów, Wesleyów, Newmanów}

W latach 2012-2019 jako wynik dwóch projektów finansowanych z Narodowego Programu Rozwoju Humanistyki opublikowano 7 tomów serii Kazania w Kulturze Polskiej. Edycje Kolekcji Tematycznych zawierających naukową edycję kazań. Na ponad 4 tysiącach stron zamieszczono teksty kazań zarówno znanych i cenionych kaznodziejów, jak i mówców minorum gentium, komentarz naukowy do nich oraz aparat krytyczny. Artykuł przestawia założenia projektów Kazania w kulturze polskiej i uczestniczące w nim zespoły badawcze, kryteria doboru tekstów kazań i ich wyniki.

Słowa kluczowe: kazanie, kaznodziejstwo, kultura, edycja naukowa, Polska

18 Przykładowo ilu współczesnych czytelników (poza specjalistami) zrozumiałoby taką frazę z kazania A. C. Załuskiego: „aby destynowany do terminalnego nieszczęścia egzekucyjej” pozostawioną bez jakiegokolwiek komentarza?

19 Np. w słowach kazania M. Karpowicza: „Słuchacie i gwałtu sobie przy łasce Boskiej do królestwa wiecznego nie czynicie” kryje się aluzja do słów Mt 11, 12: „Królestwo niebieskie doznaje gwałtu, a zdobywają je ludzie gwałtowni”. 
Abstract

\section{Showing the World the Polish Bernardino, Bossuets, Wesleys, and Newmans}

In 2012-2019, seven volumes of the Sermons in Polish Culture series were published as part of two projects subsidized by the National Program for the Development of the Humanities. The editions of the Thematic Collections contain academic editions of sermons. Texts by both famous and renowned preachers as well as lesser-known ones, academic commentary on them, and a critical apparatus span more than 4,000 pages. This article presents the assumptions of the Sermons in Polish Culture projects and the research teams that participate in them, as well as the criteria for the selection of the texts of sermons and their results.

Keywords: sermon, preaching, culture, academic edition, Poland

\section{References}

Bracha, K. (2013). Święto wiktorii grunwaldzkiej w kaznodziejstwie polskim późnego średniowiecza. In K. Ożóg \& J. Trupinda (Eds.), Conflictus magnus apud Grunwald 1410. Między historią a tradycją (pp. 231-247). Muzeum Zamkowe w Malborku.

Bracha, K. (2019). Is It Worth Publishing Anthologies of Sermons? On the Margins Kazania w kulturze polskiej. Edycje Kolekcji Tematycznych [Sermons in Polish Culture. Editions of Thematic Collections], ed. Kazimierz Panuś, vols. 1-3, Wydawnictwo UNUM, Kraków 2014, pp. 1849. Res Historica, 47, 333-348. https://doi. org/10.17951/rh.2019.47.333-348

Gazda, G., \& Tynecka-Makowska, S. (Eds.). (2006). Kazanie. In Stownik rodzajów i gatunków literackich (p. 345). Universitas.

Hanusiewicz-Lavallee, M. (2008). Współczesne metody badań nad staropolską literaturą religijną. Roczniki Humanistyczne, 56(1), 17-37.

Lewek, A. (1980). Wspótczesna odnowa kaznodziejstwa (Vol. 2). Akademia Teologii Katolickiej.

Mika, T. (2012). „Kazania świętokrzyskie”. Od rękopisu do zrozumienia tekstu. Wydawnictwo Naukowe Uniwersytetu im. Adama Mickiewicza.

Miodek, J. (1999). Współczesne kaznodziejstwo polskie. In B. Kreja (Ed.), Tysiąc lat polskiego słownictwa religijnego. Wydawnictwo Uniwersytetu Gdańskiego.

Nowicka-Jeżowa, A. (2016). Polska ars praedicandi. Od Peregryna z Opola do Karola Wojtyły. Barok. HistoriaLiteratura-Sztuka, 45/46, 247-260.

Panuś, K. (2006). Pedagogiczny wymiar kaznodziejstwa patriotycznego. In W. Janiga (Ed.), Wychowanie do patriotyzmu (pp. 529-576). Wydawnictwo Archidiecezji Przemyskiej.

Panuś, K. (2016). „Oni torowali pierwsze drogi”. Wkład kaznodziejstwa w podwaliny kultury polskiej. Ruch Biblijny i Liturgiczny, 69(4), 313-332. https://doi.org/10.21906/rbl.232

Pasierb, J. S. (1983a). Od kaznodziejstwa do homilii. Pelplin.

Pasierb, J. S. (1983b). Pionowy wymiar kultury. Znak.

Przybylski, R. (2007). Homilie na Ewangelię dzieciństwa. Sic!

Wydra, W. (2009). Wokół fenomenu „Kazań świętokrzyskich”. In P. Stępień, H. Tchórzewska-Kabata, \& I. WiniarskaGórska (Eds.), Kazania świętokrzyskie. Nowa edycja, nowe propozycje badawcze (pp. 41-58). Biblioteka Narodowa. 